\title{
ICP OES Determination of Contaminant Elements Leached from Food Packaging Films
}

\author{
Éder José dos Santos ${ }^{1 *}$, Fernanda Mara Pimentel Oliveira ${ }^{1}$, Amanda Beatriz Herrmann ${ }^{1}$, \\ Ralph Edward Sturgeon ${ }^{2}$. \\ ${ }^{l}$ Instituto de Tecnologia do Paraná - TECPAR - Centro de Tecnologia em Saúde e Meio Ambiente \\ Curitiba, Paraná, Brazil; ${ }^{2}$ Measurement Science and Standards, National Research Council Canada, Ottawa, \\ Canada.
}

\begin{abstract}
Determination of potential contaminants elements in food packing films arising from contact with acidic aqueous foods was undertaken by inductively coupled plasma optical emission spectrometry (ICP OES) in accordance with DIN EN 1186-1. Test sections from plastic films were totally immersed in $3 \% \mathrm{w} / \mathrm{v} \mathrm{CH}_{3} \mathrm{COOH}$ used as the food simulant. Testing was conducted under three conditions: (1) 10 days at $40{ }^{\circ} \mathrm{C}$; (2) 30 min at $70^{\circ} \mathrm{C}$ and 10 days at $40{ }^{\circ} \mathrm{C}$; and (3) $30 \mathrm{~min}$ at $100^{\circ} \mathrm{C}$ and 10 days at $40^{\circ} \mathrm{C}$. These time and temperature conditions were considered to be the most severe situations likely to be encountered in practice. Several different containers were investigated, including a borosilicate glass beaker, a glass bottle used for food canning, as well as one of polystyrene. The glass bottle was selected for testing treatments according to procedure (3) and a polystyrene one was chosen for use with procedures (1) and (2). Limits of quantitation were adequate for the determination of $\mathrm{Ag}, \mathrm{B}, \mathrm{Ba}, \mathrm{Cd}, \mathrm{Cr}, \mathrm{Cu}, \mathrm{Pb}, \mathrm{Sb}$, Sn and $\mathrm{Zn}$ by solution nebulization ICP OES and As by chemical vapor generation (CVG-ICP OES). Results for the analysis of AccuStandard certified reference materials as well as spike recoveries show good agreement with expected concentrations, demonstrating the accuracy and precision of the determinations. Eleven samples of food packing material were analyzed. The lead was present in the range $4.8-85.3 \mu \mathrm{g} \mathrm{L} \mathrm{L}^{-1}$ in 10 of 11 evaluated packing material, showing the importance of quality control measures.
\end{abstract}

Key words: food packaging, ICP OES, contaminant elements.

\footnotetext{
*Author for correspondence: eder@tecpar.br
} 


\section{INTRODUCTION}

Increased consumption of processed foods in recent decades implies a greater concern for the quality of packaging used with these products, since packaging materials have proven themselves to be a significant source of toxic elements that can migrate into food $\left[{ }^{1-2}\right]$. Thus, intake of a variety of elements arises from the daily diet, and in different concentrations may induce health risks as toxic elements typically have long biological half-lives, are not biodegradable and can accumulate in all living organisms $\left[^{3-5}\right]$.There is a general understanding that the packaging surface in contact with food should be free of components that may contaminate the product, since the package itself should form an effective barrier between the surface and the food, and the unintentional transfer of elements should be avoided. Thus, it is important to pay attention to the details of the packaging used for such purposes. Use of printing inks, for example, even if only on the outer surface of the package, will not ensure that the food remains contamination free, despite the inner surface being coated with films such as polyethylene and polypropylene $\left.{ }^{3,6}\right]$. There are four mechanisms by which substances used in printing inks can migrate from the printed surface to the food contact surface: blocking, rubbing, peeling and diffusion $\left[{ }^{6}\right]$. Methods for determining such migration routes and transfer efficiencies are based on use of leaching solvents that substitute for many types of foods. These replace the food product in contact with packaging, simulating the component extraction capacity from the packing while allowing use of many practical and simple analytical methodologies. The trace element content is variable because of factors such as geographical area, characteristics of the manufacturing procedures and possible contamination from the equipment used for processing, packaging and storage. It is necessary to control the manufacturing process at each step to determine the source and levels of contamination and to ensure the desired product quality. Clearly, such contaminants may compromise human health if ingested as they affect many organs of the body $\left[{ }^{7}\right]$. This study examines possible leaching by aqueous acid simulants $(\mathrm{pH} \leq 4.5)$ of antimony, arsenic, barium, boron, cadmium, lead, copper, chromium, tin, silver and zinc placed in contact with plastic packaging materials. In Brazil, RDC Resolution No. 52/2010 $\left[{ }^{8}\right]$ of the Ministry of Health establishes the maximum concentration of individual elements liable to migrate from packaging into food products and specifies the sample preparation methods to be used for the determination of contaminant elements. However, it only indicates which of the techniques have sufficient analytical detection power for such use, including ICP OES, ICP-MS (inductively coupled plasma mass spectrometry), ET AAS (electrothermal vaporization atomic absorption spectrometry), among others. In this context, Kim et al. $\left[{ }^{4}\right]$ investigated the presence of seven heavy metals in candies and candy packages using food simulant solutions under acidic ( $\mathrm{pH} 4.0)$, neutral $(\mathrm{pH}$ 7.0), and basic ( $\mathrm{pH} 10.0$ ) conditions at room temperature for their determinations by ICP OES. Raptopoulou et al. $\left[^{5}\right]$ developed and validated a method for determination of $\mathrm{As}, \mathrm{Cd}, \mathrm{Cu}, \mathrm{Cr}, \mathrm{Fe}, \mathrm{Ni}, \mathrm{Mn}$ and $\mathrm{Pb}$ by ET AAS in a study of migration phenomena in canned tomato paste; Bakircioglu et al. $\left.{ }^{7}\right]$ studied the effect of migration of metals in cheese samples packaged in tin and plastic containers using ICP OES for quantitation of the elements. Perring et al. $\left.{ }^{9}\right]$ evaluated different analytical techniques: ICP OES, ICP-MS and CVG-AAS (atomic absorption spectrometry with chemical vapor generation) for determination of $\mathrm{Cd}, \mathrm{Cr}, \mathrm{Hg}$ and $\mathrm{Pb}$ in foodpackaging materials and, more recently, Kiyataka et al. $\left[{ }^{10}\right]$ proposed a method for determination of migration of $\mathrm{As}, \mathrm{Cd}, \mathrm{Pb}$ and $\mathrm{Hg}$ through polypropylene packaging intended for contact with ice cream using $3 \% \mathrm{w} / \mathrm{v} \mathrm{CH}_{3} \mathrm{COOH}$ for leaching and ICP OES for detection. The objective of this study was to evaluate methods of preparation for the examination of packaging material in the form of films and bottle

Braz. Arch. Biol. Technol. v.60: e17160465, Jan/Dec 2017 
caps comprising polypropylene or polyethylene, as well as selection of suitable containers for this purpose and, in accordance with legislation, validate results for the determination of elemental contaminants using ICP OES.

\section{MATERIALS AND METHODS}

Instrumentation: Measurements were conducted using a VISTA PRO simultaneous axial view ICP OES (Varian, Mulgrave, Australia). Peak height emission intensities were measured for all analytes. Arsenic was determined by ICP OES using chemical vapor generation for sample introduction (CVG-ICP OES). Optimized experimental conditions are summarized in Table 1 . Argon of $99.996 \%$ purity was supplied by White Martins (São Paulo, Brazil). Friocell 222, (operating range $0.0{ }^{\circ} \mathrm{C}$ to $99.99{ }^{\circ} \mathrm{C}$ ) from MMM Medcenter Einrichtungen (Planegg, Germany) and model 400-6ND Nova Ética (São Paulo, Brazil, operating range $0.0{ }^{\circ} \mathrm{C}$ to $330.0{ }^{\circ} \mathrm{C}$ ) incubators were used for sample leaching studies.

Table 1: ICP OES instrumental parameters.

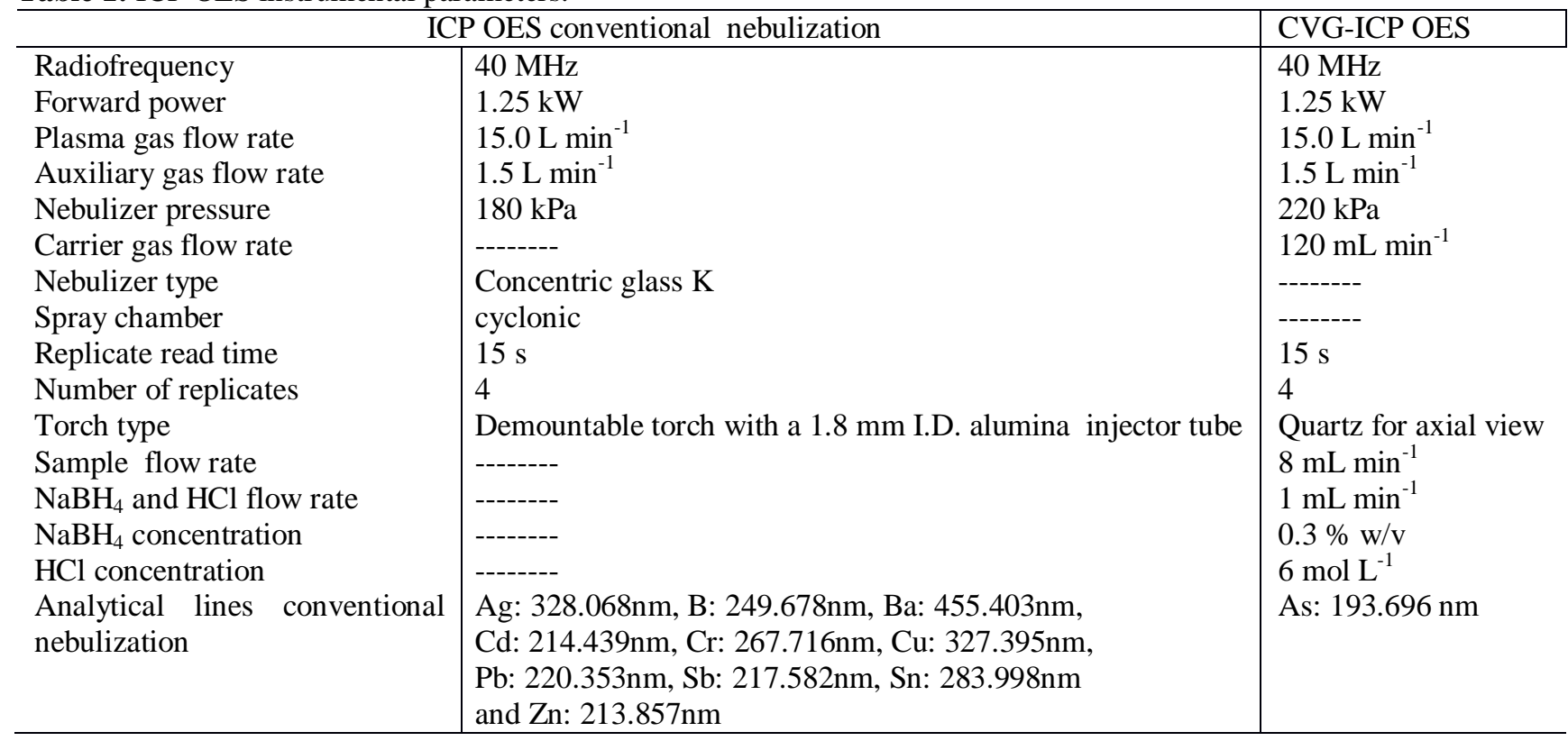

Reagents and samples: All chemicals were of analytical grade, unless otherwise specified. High purity water (resistivity of $18.2 \mathrm{M} \Omega \mathrm{cm}$ ) was de-ionized in a Milli-Q system (Bedford, MA, USA). The following reagents were used/prepared: $60 \% \mathrm{v} / \mathrm{v}$ acetic acid $\left(\mathrm{CH}_{3} \mathrm{COOH}\right.$, Panreac reagents, Barcelona, Spain) from which a $3 \% \mathrm{w} / \mathrm{v}$ solution was prepared; $\mathrm{NaBH}_{4}$ (Merck reagents, Darmstadt, Germany) from which a $1.0 \% \mathrm{w} / \mathrm{v}$ solution was stabilized in $0.4 \% \mathrm{w} / \mathrm{v} \mathrm{NaOH}$ (Merck); 37\% v/v HCl (Merck) from which a $6 \mathrm{~mol} \mathrm{~L}^{-1}$ solution was prepared for use. Monoelemental standard solutions containing $1000 \mu \mathrm{g} \mathrm{mL}^{-1}$ of $\mathrm{Ag}, \mathrm{B}, \mathrm{Pb}, \mathrm{Sb}, \mathrm{Sn}$ and $\mathrm{Zn}$ from AccuStandard (New Haven, USA) and $\mathrm{As}, \mathrm{Ba}, \mathrm{Cd}, \mathrm{Cr}, \mathrm{Cu}$ from UltraScientific (North Kingstown, USA) were used for preparation of working standards. Quality control certified reference materials containing $100 \mu \mathrm{g} \mathrm{m}^{-1}$ of $\mathrm{As}, \mathrm{Sb}, \mathrm{Cd}, \mathrm{Cr}, \mathrm{Cu}$, $\mathrm{Pb}, \mathrm{Sn}$ and $\mathrm{Zn}$ (QCS-01-5), $100 \mu \mathrm{g} \mathrm{mL}^{-1}$ and $\mathrm{Ag}$, Ba and B (QCS-02-R1-5) were sourced from AccuStandard. Samples of packing material comprising packaging films and bottle caps of polypropylene or polyethylene were obtained from Brazilian manufacturers. 
Analytical procedure: No single test method has been devised which can be used to determine overall migration, at all temperatures, in all food simulants. There are many methods that permit variations to methodology, as described in DIN EN 1186$1\left[{ }^{11}\right]$. As an acidic solution $(\mathrm{pH} \leq 4.5), 3 \% w / v \mathrm{CH}_{3} \mathrm{COOH}$ is designated by DIN EN $\left.1186-1{ }^{11}\right]$ and is termed herein as "simulant B". In accord with this norm, test specimens were prepared by cutting sections from the plastic and totally immersing them in this solution. The surface-to-volume ratio for this total immersion test is conventionally $1 \mathrm{dm}^{2}$ of plastic food contact area to $100 \mathrm{~mL}$ of food simulant, i.e,, $3 \% w / v \mathrm{CH}_{3} \mathrm{COOH}$ for acidic aqueous foods. In our laboratory, three methods are currently adopted: (1) where the food packaging is labeled for use at room temperature or below or where the food packaging, by its nature, is clearly intended for use at room temperature and below, the test was conducted over the course of 10 days at $40^{\circ} \mathrm{C} ;(2)$ when the food packaging was intended to be subjected to a hot fill, i.e., in the preparation of the food, the test is first conducted for $30 \mathrm{~min}$ at $70{ }^{\circ} \mathrm{C}$ followed by 10 days at $40{ }^{\circ} \mathrm{C}$; and (3) 30 min leaching at $100{ }^{\circ} \mathrm{C}$ followed by 10 days at $40{ }^{\circ} \mathrm{C}$. These conditions of time and temperature were considered to be the most severe situations to be encountered [ $\left.{ }^{11}\right]$. Samples were cut to provide an area of 1 $\mathrm{dm}^{2}(10 \mathrm{~cm} \times 10 \mathrm{~cm})$ and transferred to a $690 \mathrm{~mL}$ polystyrene flask (Product No. 90150, Techno Plastic Products AG, Trasadingen, Switzerland) having dimensions of $10 \times 122 \times 50 \mathrm{~mm}(1 \times \mathrm{x} \mathrm{x} \mathrm{h})$ and growth surface of $150 \mathrm{~cm}^{2}$ for application of methods 1 and 2, whereas for application of procedure 3, a $500 \mathrm{~mL}$ glass flask of dimensions of $70 \times 140 \mathrm{~mm}(\varnothing \mathrm{x} \mathrm{h})$ was employed. The required volume of $3 \% \mathrm{w} / \mathrm{v}$ $\mathrm{CH}_{3} \mathrm{COOH}$ solution was added and the test samples were completely immersed in the leachate. Following this leaching procedure, the simulant solution was subjected to analysis of the selected elements by ICP OES. To evaluate the recovery, precision and bias of the methodology, 21 solutions spiked with all the analytes in 3\% w/v $\mathrm{CH}_{3} \mathrm{COOH}$ (prepared from individual stock solutions) and three replicate solutions also in 3\% w/v $\mathrm{CH}_{3} \mathrm{COOH}$ (prepared from AccuStandard quality control certified reference materials) were subjected to the various leaching methodologies.

\section{RESULTS AND DISCUSSION}

\section{Figures of merit}

Calibration curves prepared from multielement standards $(\mathrm{Ag}, \mathrm{B}, \mathrm{Ba}, \mathrm{Cd}, \mathrm{Cr}, \mathrm{Cu}, \mathrm{Pb}$, $\mathrm{Sb}, \mathrm{Sn}$ and $\mathrm{Zn}$ ) in a $3 \% \mathrm{w} / \mathrm{v} \mathrm{CH}_{3} \mathrm{COOH}$ medium spanned a concentration range 100 $-2000 \mu \mathrm{g} \mathrm{L}^{-1}$ and were introduced using conventional solution nebulization under the conditions summarized in Table 1 - ICP OES conventional nebulization. For As, the concentration range of the calibration solutions prepared in $3 \% \mathrm{w} / \mathrm{v} \mathrm{CH}_{3} \mathrm{COOH}$ was $5.0-15.0 \mu \mathrm{g} \mathrm{L}^{-1}$. These were processed using the conditions summarized in Table 1 - CVG-ICP OES system. The linear regression coefficients, estimated limits of detection (LODs) and the practical quantification limits (LOQs) are summarized in Table 2 along with the legislated Brazilian limits $\left[{ }^{8}\right]$. The LOD was calculated as 3-times the standard deviation of 7 measurements of the blank divided by the slope of the calibration curve whereas the LOQ was based on 10-times the standard deviation of the blank and yields an estimate of the lowest concentration which can be determined with acceptable precision and accuracy $\left[{ }^{12}\right]$. Calibration linearity and the LOQs are fit-for-purpose for the determination of these analytes in the leaching solutions intended to come into contact with food packaging materials as they meet the limits set by Brazilian legislation. 
Metals in food packaging films

Table 2: Regression coefficients, limits of detection and quantification for analytical calibration functions prepared in $3 \% \mathrm{w} / \mathrm{v} \mathrm{CH}_{3} \mathrm{COOH}$.

\begin{tabular}{ccccc}
\hline Analyte & $\begin{array}{c}\text { Linear regression } \\
\text { coefficients }\end{array}$ & $\begin{array}{c}\text { Limit of detection, } \\
\mu \mathrm{g} \mathrm{L}^{-1}\end{array}$ & $\begin{array}{c}\text { Practical quantification } \\
\text { limits, } \mu \mathrm{g} \mathrm{L}^{-1}\end{array}$ & $\begin{array}{c}\text { Brazilian legislated limits } \\
\text { RDC 52, } \mu \mathrm{g} \mathrm{L}^{-1}\end{array}$ \\
\hline $\mathrm{Ag}$ & 0.9998 & 0.2 & 2.0 & 50 \\
$\mathrm{As}$ & 0.9981 & 0.2 & 2.0 & 10 \\
$\mathrm{Ba}$ & 0.9997 & 0.2 & 2.0 & 1,000 \\
$\mathrm{~B}$ & 0.9997 & 1.0 & 10 & 500 \\
$\mathrm{Cd}$ & 0.9999 & 0.1 & 1.0 & 5 \\
$\mathrm{Cr}$ & 0.9999 & 0.1 & 1.0 & 50 \\
$\mathrm{Cu}$ & 0.9998 & 1.0 & 10 & 1000 \\
$\mathrm{~Pb}$ & 0.9999 & 0.2 & 2.0 & 40 \\
$\mathrm{Sb}$ & 0.9997 & 2.0 & 20 & 1,200 \\
$\mathrm{Sn}$ & 0.9999 & 5.0 & 50 & 25,000 \\
$\mathrm{Zn}$ & 0.9999 & 1.0 & 50 & \\
\hline
\end{tabular}

Selection of an appropriate container for sample treatment

Several containers were investigated for their suitability for sample treatment based on their method blanks when submitted to different leaching scenarios. Three different containers were investigated: flask 1: a borosilicate glass beaker; flasks 2 and 3: two different glass bottles used for food canning, and flask 4: a polystyrene container (from TPP). Containers 1-3 were treated as described for use with method $3\left(30 \mathrm{~min}\right.$ at $100{ }^{\circ} \mathrm{C}$ followed by 10 days at $40{ }^{\circ} \mathrm{C}$ ), and identified as the most severe method in terms of temperature; flask 04 was used with method $2\left(30 \mathrm{~min}\right.$ at $70{ }^{\circ} \mathrm{C}$ followed by 10 days at $40{ }^{\circ} \mathrm{C}$ ). After the prescribed period of ten days, the leach solutions were analyzed for the elements of interest by ICP OES. Results are presented in Table 3. Flask 1, a $400 \mathrm{~mL}$ beaker, was simply covered with a watchglass and submitted to the test. The major disadvantage of its use was the loss of the leaching solution by evaporation as it is difficult to properly fit a cover over this container. The final solutions lost approximately $10 \%$ of their initial volume, requiring makeup solution to be added. A further problem was the possibility of loss of some elements, such as $\mathrm{As}, \mathrm{Sb}$ and $\mathrm{Pb}$, by volatilization, yielding poor accuracy for the final results. Due to these shortcomings, this container was concluded to be not suitable for its intended purpose. Flasks 2 and 3 are glass bottles used for food canning which have suitable covers to prevent losses due to evaporation of the analytes or vaporization of the leachate. However, flask 2 was manufactured from recycled glass and some contaminants, mainly $\mathrm{Pb}$ and $\mathrm{Zn}$, were leached from its interior surface. For this reason it was deemed inappropriate for use in these tests. Flask 3 showed good performance and was selected as the most suitable for sample treatment requiring a temperature of $100{ }^{\circ} \mathrm{C}$. Flask 4, unlike the others, was manufactured from polystyrene, a high purity material that did not show the presence of contaminants in its structure and was therefore suitably inert for the testing of film samples of packaging at temperatures of $70{ }^{\circ} \mathrm{C}$ and $40{ }^{\circ} \mathrm{C}$ (methods 1 and 2). However, this container could not be employed with method 3 due to the need for a leaching temperature of $100{ }^{\circ} \mathrm{C}$ since polystyrene has a glass transition temperature of $105.1^{\circ} \mathrm{C}\left[{ }^{6}\right]$. Flask 3 was thus used exclusively for this method. 
Table 3: Method blanks obtained from 3\% w/v $\mathrm{CH}_{3} \mathrm{COOH}$ leaching of four different containers, $(\mathrm{n}=3)$.

\begin{tabular}{lllll}
\hline Analyte & $\mu \mathrm{g} \mathrm{L}^{-1}$ & & \\
\cline { 2 - 4 } & Flask 1 & Flask 2 & Flask 3 & Flask 4 \\
\hline $\mathrm{Ag}$ & $<2.0$ & $<2.0$ & $<2.0$ & $<2.0$ \\
$\mathrm{As}$ & $<2.0$ & $<2.0$ & $<2.0$ & $<2.0$ \\
$\mathrm{Ba}$ & $<2.0$ & $5.4 \pm 0.1$ & $<2.0$ & $<2.0$ \\
$\mathrm{~B}$ & $<10$ & $<10$ & $<10$ & $<10$ \\
$\mathrm{Cd}$ & $<1.0$ & $<1.0$ & $<1.0$ \\
$\mathrm{Cr}$ & $<1.0$ & $<10$ & $<1.0$ & $<1.0$ \\
$\mathrm{Cu}$ & $<1.0$ & $28.9 \pm 1.3$ & $<10$ & $<10$ \\
$\mathrm{~Pb}$ & $<10$ & $<20$ & $<2.0$ & $<2.0$ \\
$\mathrm{Sb}$ & $<2.0$ & $<50$ & $<20$ & $<20$ \\
$\mathrm{Sn}$ & $<20$ & $61.5 \pm 0.3$ & $<50$ & $<50$ \\
$\mathrm{Zn}$ & $<50$ & & $<50$ & $<50$ \\
\hline
\end{tabular}

\section{Precision and bias of the methodology}

Technically, ICP OES and CVG-ICP OES are appropriate instrumental methods of analysis, being sufficiently sensitive and presenting LOQs below those required by Brazilian legislation (2-500-fold lower, for $\mathrm{Sb}$ and $\mathrm{Ba}$, respectively). The precision of the methodology varies for the 21 solutions of $3 \% \mathrm{w} / \mathrm{v} \mathrm{CH}_{3} \mathrm{COOH}$ spiked at a final concentration of $20 \mu \mathrm{g} \mathrm{L}^{-1}$ for $\mathrm{Ag}, \mathrm{As}, \mathrm{Ba}, \mathrm{Cd}, \mathrm{Cr}, \mathrm{Cu}, \mathrm{Pb}$ and $\mathrm{Sb}$ and $100 \mu \mathrm{g} \mathrm{L}$ ${ }^{1}$ for $\mathrm{Sn}$ and $\mathrm{Zn}$. Solutions were transferred to the appropriate flasks and subjected to test methods 1-3 to evaluate both spike recovery against external calibration functions, as well as the precision of determination (repeatability) on multiple $(n=7)$ preparations. Results are presented in Table 4.

Table 4: Spike recovery from solutions of $3 \% \mathrm{w} / \mathrm{v} \mathrm{CH}_{3} \mathrm{COOH}(\mathrm{n}=7)$.

\begin{tabular}{lllll}
\hline Analyte & $\begin{array}{l}\text { Concentration } \\
\text { added, } \mu \mathrm{g} \mathrm{L}\end{array}$ & \multicolumn{3}{l}{ Concentration determined, $\mu \mathrm{g} \mathrm{L}^{-1}$} \\
\cline { 3 - 5 } & 20.0 & Method 1 & Method 2 & Method 3 \\
\hline $\mathrm{Ag}$ & 20.0 & $21.1 \pm 0.3$ & $21.1 \pm 0.8$ & $20.6 \pm 1.0$ \\
$\mathrm{As}$ & 20.0 & $19.5 \pm 1.1$ & $20.8 \pm 0.7$ & $20.4 \pm 2.0$ \\
$\mathrm{Ba}$ & $20.8 \pm 0.2$ & $20.8 \pm 0.4$ & $20.9 \pm 0.6$ \\
$\mathrm{~B}$ & 20.0 & $20.4 \pm 1.1$ & $19.8 \pm 1.9$ & $21.6 \pm 1.6$ \\
$\mathrm{Cd}$ & 20.0 & $20.7 \pm 0.5$ & $20.3 \pm 0.6$ & $20.8 \pm 0.8$ \\
$\mathrm{Cr}$ & 20.0 & $20.6 \pm 0.4$ & $20.2 \pm 0.8$ & $20.7 \pm 0.4$ \\
$\mathrm{Cu}$ & 20.0 & $20.7 \pm 1.0$ & $20.3 \pm 1.0$ & $20.3 \pm 0.7$ \\
$\mathrm{~Pb}$ & 20.0 & $22.3 \pm 1.8$ & $20.9 \pm 0.7$ & $20.7 \pm 1.0$ \\
$\mathrm{Sb}$ & 20.0 & $107.5 \pm 2.7$ & $22.8 \pm 2.0$ & $21.8 \pm 2.1$ \\
$\mathrm{Sn}$ & 100.0 & $113.7 \pm 1.7$ & $107.0 \pm 1.8$ & $102.1 \pm 1.5$ \\
$\mathrm{Zn}$ & 100.0 & $98-114$ & $99.2 \pm 1.2$ & $107.0 \pm 1.0$ \\
\hline Recovery, range (\%) & & $0.6-8.1$ & $1.2-9.6$ & $102-107$ \\
$\mathrm{RSD}$, range (\%) & & & & $0.9-9.8$ \\
\hline
\end{tabular}

Analysis of the solutions prepared in $3 \% \mathrm{w} / \mathrm{v} \mathrm{CH}_{3} \mathrm{COOH}$ provides excellent agreement (recoveries within $98-114 \%$ ) with expected concentrations characterized by relative standard deviations (RSD) below $10 \%$, indicating that fitfor-purpose recovery and precision can be achieved following the prescribed sample preparation procedures and instrumental calibration $\left[{ }^{12}\right]$. To evaluate the accuracy, measurements of three replicate solutions of the quality control certified reference materials (AccuStandard) QCS-01-5 and QCS-02-R1-5 appropriately diluted in 3\% w/v $\mathrm{CH}_{3} \mathrm{COOH}$ were performed following the three methods of extraction. Results are presented in Table 5, from which good agreement with the expected concentrations has been achieved (recoveries from 92 to 104\%) demonstrating good accuracy $\left[{ }^{12}\right]$. Thus, flasks 3 and 4 are suitable and stable for application to all 
Metals in food packaging films

analytes over the contact time and temperatures employed, considering there were no losses due to surface adsorption or volatilization.

Table 5: Results for analysis of quality control materials $(n=3)$.

\begin{tabular}{|c|c|c|c|c|}
\hline \multirow[t]{2}{*}{ Analyte } & \multirow{2}{*}{$\begin{array}{l}\text { Concentration } \\
\text { present } \\
\mu \mathrm{g} \mathrm{L}^{-1}\end{array}$} & \multicolumn{3}{|c|}{ Concentration obtained, $\mu \mathrm{g} \mathrm{L}^{-1}$} \\
\hline & & Method 1 & Method 2 & Method 3 \\
\hline $\mathrm{Ag}$ & 50.0 & $46.1 \pm 0.6$ & $51.8 \pm 0.3$ & $52.0 \pm 0.6$ \\
\hline As & 50.0 & $49.5 \pm 0.7$ & $50.0 \pm 1.0$ & $48.6 \pm 1.6$ \\
\hline $\mathrm{Ba}$ & 50.0 & $49.8 \pm 0.1$ & $49.8 \pm 0.2$ & $50.8 \pm 0.7$ \\
\hline B & 50.0 & $50.4 \pm 1.1$ & $51.8 \pm 2.0$ & $46.6 \pm 1.6$ \\
\hline $\mathrm{Cd}$ & 50.0 & $50.6 \pm 0.2$ & $50.5 \pm 0.1$ & $50.3 \pm 0.3$ \\
\hline $\mathrm{Cr}$ & 50.0 & $50.7 \pm 0.2$ & $50.7 \pm 0.4$ & $50.2 \pm 0.2$ \\
\hline $\mathrm{Cu}$ & 50.0 & $46.3 \pm 0.5$ & $49.8 \pm 1.0$ & $47.3 \pm 0.1$ \\
\hline $\mathrm{Pb}$ & 50.0 & $48.9 \pm 0.8$ & $47.9 \pm 2.2$ & $50.0 \pm 1.3$ \\
\hline $\mathrm{Sb}$ & 50.0 & $49.3 \pm 2.2$ & $48.6 \pm 2.2$ & $49.1 \pm 1.9$ \\
\hline $\mathrm{Sn}$ & 50.0 & $49.2 \pm 1.7$ & $47.7 \pm 2.4$ & $46.4 \pm 2.1$ \\
\hline $\mathrm{Zn}$ & 50.0 & $52.0 \pm 0.1$ & $47.5 \pm 0.4$ & $50.9 \pm 0.1$ \\
\hline
\end{tabular}

Similar results for the various analytes, independent of the applied methodology used for leaching potential contaminants from the tested materials (scenarios 1-3) are evident from the data in Tables 4 and 5. This suggests that a simple leach time of 10 days at $40{ }^{\circ} \mathrm{C}$ is sufficient to account for all leachable impurities in the samples examined and that excursions to elevated test temperatures of 70 and $100{ }^{\circ} \mathrm{C}$ do not have a significant impact for the materials examined.

\section{Analytical application}

Eleven industrial samples of packaging material and several bottle caps were selected for analysis; results are presented in Table 6.

Table 6: Analyses of eleven samples of packaging material and bottle caps $\left(\mu \mathrm{g} \mathrm{L}^{-1}, \mathrm{n}=3\right)$.

\begin{tabular}{|c|c|c|c|c|c|c|c|}
\hline Sample & $\mathrm{Ag}$ & $\mathrm{Ba}$ & B & $\mathrm{Cr}$ & $\mathrm{Cu}$ & $\mathrm{Pb}$ & $\mathrm{Zn}$ \\
\hline $01^{(1)}$ & $<2.0$ & $4.7 \pm 1.4$ & $13 \pm 2$ & $2.2 \pm 0.4$ & $<10$ & $85.3 \pm 1.9$ & $<50$ \\
\hline $02^{(1)}$ & $<2.0$ & $5.2 \pm 0.6$ & $14 \pm 1$ & $1.3 \pm 0.5$ & $<10$ & $37.2 \pm 5.0$ & $<50$ \\
\hline $03^{(1)}$ & $<2.0$ & $6.3 \pm 1.1$ & $16 \pm 3$ & $3.2 \pm 0.1$ & $<10$ & $14.3 \pm 1.3$ & $<50$ \\
\hline $04^{(2)}$ & $<2.0$ & $2.1 \pm 0.3$ & $<10$ & $1.2 \pm 0.2$ & $<10$ & $<2.0$ & $51 \pm 5$ \\
\hline $05^{(1)}$ & $<2.0$ & $2.5 \pm 0.7$ & $<10$ & $3.3 \pm 0.8$ & $<10$ & $18.2 \pm 3.0$ & $154 \pm 14$ \\
\hline $06^{(1)}$ & $<2.0$ & $3.2 \pm 0.5$ & $<10$ & $2.2 \pm 0.5$ & $<10$ & $15.0 \pm 0.6$ & $210 \pm 9$ \\
\hline $07^{(1)}$ & $<2.0$ & $<2.0$ & $<10$ & $7.1 \pm 1.2$ & $<10$ & $4.6 \pm 0.9$ & $73 \pm 8$ \\
\hline $08^{(1)}$ & $<2.0$ & $2.4 \pm 0.3$ & $<10$ & $<1.0$ & $<10$ & $14.0 \pm 0.8$ & $<50$ \\
\hline $09^{(1)}$ & $2.4 \pm 0.4$ & $61.6 \pm 0.9$ & $35.0 \pm 1.6$ & $<1.0$ & $<10$ & $27.3 \pm 2.6$ & $229 \pm 50$ \\
\hline $10^{(1)}$ & $<2.0$ & $7.9 \pm 0.6$ & $11.4 \pm 0.9$ & $2.1 \pm 0.2$ & $13 \pm 1$ & $71.8 \pm 2.0$ & $51 \pm 1$ \\
\hline $11^{(3)}$ & $<2.0$ & $4.3 \pm 0.1$ & $<10$ & $<1.0$ & $<10$ & $4.8 \pm 0.1$ & $51 \pm 1$ \\
\hline Legislation & $50 \max$ & 1,000 max. & 500 max. & 50 max. & 5,000 max. & 10 max. & 25,000 max. \\
\hline
\end{tabular}

Arsenic was not detected below $2.0 \mu \mathrm{g} \mathrm{L}^{-1}$, Cd was not detected below $1.0 \mu \mathrm{g} \mathrm{L}{ }^{-1}, \mathrm{Sb}$ was not detected below $20 \mu \mathrm{g} \mathrm{L}^{-1}$ and Sn was not detected below $50 \mu \mathrm{g} \mathrm{L}^{-1}$ in any of the samples. Only $\mathrm{Pb}$ was detected above the maximum allowed under Brazilian legislation in 8 of the 11 samples examined $\left[^{8}\right]$. Human exposure to $\mathrm{Pb}$ causes a variety of health effects, particularly in children. Toxic effects are usually due to long-term exposure $\left[{ }^{13}\right]$. The use of polymer-based packaging for contact with food has grown in recent years, and the consumption of processed products is the reason for this increase. Lead, present as a contaminant in food additives which are part of the packaging, migrates to the food, indicating a recorded failure in the packaging industry, in the food industry and regulatory agencies, demonstrating that these 
quality processes require better control. Thus, the quality of raw materials purchased by industries deserves particular attention, since they become packaging for foods, exposing the consumer to ingested contaminants $\left[{ }^{10,14}\right]$. These samples were therefore disapproved for final use as food packaging. The other elements of interest were present at concentrations below the values specified by law. Nevertheless, such studies validate the conclusions that contaminant elements migrate from food packaging materials and those such as $\mathrm{Cr}$ and $\mathrm{Ba}$ may thus be present in food, even at low concentrations.

\section{CONCLUSIONS}

Validation studies indicate that the containers selected for study are suitable for the evaluation of migration of contaminant elements from plastic films used in the manufacture of food packaging materials. Analytical techniques such as ICP OES, including chemical vapor generation utilized for the quantification of As, present acceptable precision and accuracy. Results for leaching of plastic films revealed that $\mathrm{Pb}$, in most samples, was the main contaminant in contravention to legislated limits detected, suggesting that the industry needs to review the manufacturing process for packaging materials so as to ensure the quality of foods.

\section{ACKNOWLEDGEMENTS}

The authors are thankful to Conselho Nacional de Desenvolvimento Científico e Tecnológico (CNPq, Project 456764/2013-5: Manutenção da Rede de Laboratórios de Resíduos e Contaminantes MAPA/MCTI, Brazil) for scholarship to Fernanda Mara Pimentel Oliveira and Financiadora de Estudos e Projetos (FINEP, Brazil) for financial support.

\section{REFERENCES}

1- Thompson, D., Parry, S. J. \& Benzing, R. (1997). The validation of a method for determining the migration of trace elements from food packaging materials into food. Journal of Radioanalytical and Nuclear Chemistry, 217 (1), 147-150.

2- Nerin, C., Alfaro, P., Aznar, M. \& Domeño, C. (2013). The challenge of identifying nonintentionally added substances from food packaging materials: A review. Analytica Chimica Acta, 775, 14-24.

3- Arvanitoyannis, I. S. \& Kotsanopoulos, K. V. (2014). Migration phenomenon in food packaging. Food-package interactions, mechanisms, types of migrants, testing and relative legislation - a review. Food and Bioprocess Technology, 7, 21-36.

4- Kim, K. C., Park, Y. B., Lee, M. J., Kim, J. B., Huh, J. W., Kim, D. H., Lee, J. B. \& Kim, J. C. (2008). Levels of heavy metals in candy packages and candies likely to be consumed by small children. Food research international, 41, 411-418.

5- Raptopoulou, K. G., Pasias, I. N., Thomaidis, N. S. \& Proestos, C. (2014). Study of the migration phenomena of specific metals in canned tomato paste before and after opening. Validation of a new quality indicator for opened cans. Food and Chemical Toxicology, 69, 25-31.

6- Lahimer, M. C., Ayed, N., Horriche, J. \& Belgaied, S. (2013). Characterization of plastic packaging additives: food contact, stability and toxicity. Arabian Journal of Chemistry. In Press. Available in http://dx.doi.org/10.1016/j.arabjc.2013.07.022>. Access in 15/04/2015.

7- Bakircioglu, D., Kurtulus, Y. B., \& Ucar, G. (2011). Determination of some traces metal levels in cheese samples packaged in plastic and tin containers by ICP-OES after dry, wet and microwave digestion. Food and Chemical Toxicology, 49, 202-207.

8- RDC $\mathrm{N}^{\circ} 52$ of 11/26/2010: describes about colorants in plastic packaging and equipment designed to be in contact with food, item 3: tests for packaging and printed plastic 
Metals in food packaging films

equipment and/or containing colorants in its formulation, intended to come into contact with food - ANVISA, Brazil, 2010.

9- Perring, L., Alonso, M. I., Andrey, D., Bourqui B. \& Zbinden, P. (2001). An evaluation of analytical techniques for determination of lead, cadmium, chromium, and mercury in food-packaging materials. Fresenius J, Anal. Chem., 370, 76-81.

10-Kiyataka, P.H.M., Dantas, S.T. \& Pallone, J.A.L. (2015). Method for Analysis and Study of Migration of Lead, Cadmium, Mercury and Arsenic from Polypropylene Packaging into Ice Cream and Simulant. Food Anal. Methods, 8, 2331-2338.

11-European Committee for Standardization - EN 1186-1: describes about materials and articles in contact with foodstuffs - plastics. Part 1: guide to the selection of conditions and test methods for overall migration. Brussels, 2002. p.49.

12-Miller, J. N., Miller, J. C. Statistics and Chemometrics for Analytical Chemistry. $5^{\text {th }}$ ed. Edinburgh: Person Education; 2000.

13-Montanari, A. Inorganic Contaminants of Food as a Function of Packaging Features, Chapter 2. Available in <file:///C:/Users/eder/Downloads/9783319148267-c2.pdf >. Access in 20/10/2015.

14-Kiyataka, P.H.M. (2013). Lead, cadmium, mercury and arsenic in polymeric food packaging by ICP OES. Campinas, 2013. Master dissertation. Faculty of Food Engineering, State University of Campinas. 